\title{
Ageing in Austria: An overview of "Survey of Health, Ageing and Retirement in Europe" (SHARE) with special focus on aspects of health
}

\author{
Isabella Buber *
}

\begin{abstract}
After a short introduction to the "Survey of Health, Ageing and Retirement in Europe" (SHARE) we present results for Austria focusing on different aspects of health. Among Austrians aged 50 and above - especially at higher ages - strong gender-specific differences are observed for physical health, mental health and disabilities. Older persons getting help due to difficulty with IADLs and/or ADLs mostly receive the assistance that meets their needs. Social support is rather common. On the one hand, three out of ten older persons reported that they personally or their spouses or partners have received help from any family member, friend or neighbour outside the household during the past twelve months. On the other, one out of four persons aged 50 and more reported to have given help to others. Children living outside the household provide an essential support for their parents. The network of the older persons is rather diverse, especially of those living alone.
\end{abstract}

\section{SHARE Europe}

In this article, we want to give a short introduction to the "Survey of Health, Ageing and Retirement in Europe" (SHARE) and present results for Austria for different aspects of health.

Europe's population is becoming older and older and population projections predict that in 2050 about half of the EU-15's population will be aged 50 or above (Scherbov and Mamolo 2006). In view of such an important shift in the composition of the population, it was high time to collect comparable data on individual life circumstances for the growing group of older persons in Europe.

\footnotetext{
* Vienna Institute of Demography, Austrian Academy of Sciences, Wohllebengasse 12-14, 6th fl., 1040 Vienna, Austria; Email: isabella.buber@oeaw.ac.at
} 
"Understanding ageing and how it affects individuals in the diverse cultural settings of Europe is the main task of SHARE" (Börsch-Supan et al. 2005, p. 8).

The "Survey of Health, Ageing and Retirement in Europe" (SHARE) is the first European dataset that includes accurate cross-national information on economic circumstances, health, well-being, integration into family and social networks for the following twelve-mainly continental European - countries: Austria, Belgium, Denmark, France, Germany, Greece, Israel, Italy, the Netherlands, Spain, Sweden, and Switzerland. It aims at understanding the ageing process in Europe in order to turn "potential challenges into chances" (BörschSupan 2005, p.1). SHARE was created to follow the English Longitudinal Survey of Ageing (ELSA) and the American Health and Retirement Survey (HRS) but also faced new challenges. Besides the comparability with HRS and ELSA, a main goal was to accommodate the needs of the different European countries. On the one hand, the survey had to cater to a wide variety of social institutions specialising on health care or retirement in the countries it covered; on the other hand, the setup and content of the questionnaire had to be strictly comparable across countries so as to allow researchers to use the data quickly without having to go back to the national institutions.

SHARE is a "multidisciplinary enterprise with a strong emphasis on looking always from at least three angles: economics, health, and social networks" (Börsch-Supan et al. 2005, p. 18). The research team is characterised by a good balance of scientists representing many disciplines: demography, economics, sociology, epidemiology, statistics, social psychology, psychiatry, public health and many more. The main idea has been to provide comparable information on all aspects of ageing in European countries. The survey is subdivided into 21 modules. It starts with the coverscreen (CV) module, which is crucial for linking members of a household, and the demographic (DN) module. The other 19 modules cover a great variety of aspects of ageing: physical health $(\mathrm{PH})$, behavioural risks (BR), cognitive function (CF), mental health $(\mathrm{MH})$, health care (HC), employment and pensions (EP), grip strength (GS), walking speed (WS), children $(\mathrm{CH})$, social support (SP), financial transfers (FT), housing (HO), household income (HH), consumption (CO), assets (AS), activities (AC), expectations (EX), interviewer observations (IV) and a self-administered questionnaire (Q). Apart from the 21 modules of the main SHARE questionnaire, additional modules were produced that include weights, generated variables on education, health, housing, occupation, support and household composition as well as an extensive set of generated and imputed variables on income and assets.

The first wave of data collection was carried out between 2004 and 2006, "Release 2.0.1" has been available since July 2007. As the survey has been financed by public money ${ }^{1}$, scientific research should profit from it to the

Funding for the SHARE data collection was mainly provided by the European Commission within the $5^{\text {th }}$ Framework Programme, additional funding came from the US National Institute on Aging, moreover some SHARE countries also had national co-funding. In three countries, 
maximum possible extent. SHARE has an open access policy, data can be accessed by all researchers free of charge. ${ }^{2}$

The second wave of data collection was conducted from autumn 2006 through to summer 2007. SHARE is to expand and will include new accession countries, namely Ireland, Poland, and the Czech Republic which had their first wave in 2007. In analogy to the American HRS, a biennial survey schedule is planned for the more distant future. Moreover, a module on life histories focusing on employment, family affairs and health is planned as an interim wave for 2008/2009.

SHARE is based on probability samples in all participating countries and represents the non-institutionalised population aged 50 and older. Since spouses of persons aged 50 and above were also interviewed, some persons in the dataset are younger than 50. "Release 2.0.1" comprises data on an unweighted total of 31,115 individuals in 21,176 households (in twelve countries). The weighted average response rate is $61.6 \%$, and the within-household response rate ${ }^{3}$ is $85.3 \%$. Comparisons with three prominent other European surveys-i.e., the quarterly European Union Labour Force Survey (EU-LFS), the European Community Household Panel (ECHP) and the European Social Security Survey (ESS) - show that the key statistics on employment, income, education and health are very similar and rarely statistically different (Börsch-Supan et al. 2005). SHARE is a reliable dataset and contains all essential elements on the population aged 50 and above in Europe.

As it is very important to understand which individuals are being interviewed, we briefly summarise the individuals included in the SHARE data:

- persons aged 50 or older,

- their partners, if they are living in the same household, even if they are less than 50 years old,

- their parents or parents-in-law, if they are living in the same household (who will definitely be older than 50),

- their children, if they are living in the same household and are already aged 50 or older,

- their relatives such as brothers or sisters, if they are living in the same household and are aged 50 or older,

- other persons aged 50 and older, if they are living in the same household.

The sample does not include people such as children or grandchildren below age 50 who live in the same household. Moreover, as already mentioned above,

data were for the most part nationally funded: Austria (by the Austrian Science Foundation, FWF), Belgium and Switzerland.

2 See http://www.share-project.org/index.php?page=Accessthedata\&menue $=5 \&$ sub $=$

3 The within-household response rate is defined as the ratio between the number of responding individuals and the number of eligible persons in these households (Börsch-Supan and Jürges 2005, p. 99). 
SHARE does not capture individuals living in institutions. ${ }^{4}$ Since SHARE is designed as a longitudinal survey, future waves of SHARE will also include persons living in institutions for older persons, as SHARE follows the individuals over time. In order to have a representative sample, weights were designed both on the individual and on the household level, they take into account the distribution of persons aged 50 and above by age and sex. ${ }^{5}$

Börsch-Supan et al. (2005) presented first results on all SHARE modules, in January 2007 about 500 user IDs were counted and it is supposed that the number of users is even much higher. This indicates that SHARE is used intensively within the scientific community and the release of the second wave will make these data even more attractive allowing longitudinal analyses.

\section{Austrian SHARE data}

Rudolf Winter-Ebmer from the Department of Economics of the Johannes Kepler University Linz is the Austrian country team leader who coordinates data collection and research in Austria and cooperates - among others-with the Vienna Institute of Demography (VID). In 2006, VID created a codebook for the whole survey (Buber 2006), investigated much effort in meticulous data examination and reconciliation of conflicting information and therefore provided the Mannheim Research Institute for Economics of Aging (MEA) - the managing institute of SHARE - with useful information for data cleaning. The research group at VID working on SHARE benefited tremendously from our visitors Elsie Pamuk from the National Center for Health Statistics (NCHS) and the independent researcher Harold Lentzner with an adjunct appointment at the University of Southern California.

SHARE data were collected by national, mainly private survey institutes. In Austria, this task was assigned to IMAS ("Institut für Markt- und Sozialanalyse"). The Austrian target population were all households with at least one Germanspeaking member born in 1954 or earlier. All German-speaking residents in the sample who were born in 1954 or earlier and their spouses/partners at the time of the interview were selected for interviews.

The Austrian SHARE data include an unweighted total of 1,893 individuals782 men and 1,111 women - in 1,404 households, with a household response rate of $55.6 \%$ and an individual response rate of $87.5 \%$. The Austrian household response rate of $55.6 \%$ indicates that in $55.6 \%$ of all households at least one person was willing to answer the questionnaire. These $55.6 \%$ are an unweighted total of 1,404 households. The individual response rate of $87.5 \%$ shows that

4 As an exception, in Denmark persons living in institutions for older persons were also included in the sample.

5 There are no weights for individuals below 50, as these persons are not a representative sample of the population below 50 years of age. 
$87.5 \%$ of all eligible persons in the 1,404 households were successfully interviewed. We briefly provide some basic information on the Austrian data: the youngest Austrian respondent was a woman aged 35, the oldest was one of 99 years. Since weights are available only for the population aged 50 and above, younger respondents - who entered as partners of persons aged 50+-were excluded from further analyses. We are therefore left with an unweighted total of 1,839 respondents aged 50 and above (776 men and 1,063 women), living in 1,397 households.

In this article we want to concentrate on Austrian data and focus on different aspects of health: physical health, mental health, cognitive functioning and disabilities among older persons in Austria. ${ }^{6}$ Buber et al. (2006) gave an overview of all variables coded in the Austrian SHARE dataset, we refer to this publication for further details on the distribution of all variables included in the 21 modules. Our weighted sample comprises 1,839 individuals, 818 men and 1,021 women aged 50 and above, i.e., there is a dominance of women in the dataset. Figure 1 shows the distribution of Austrian respondents aged 50 and above by sex and age. The relatively high number of women aged 80 and above as compared to men is due both to losses of men during World War II and to women's higher life expectancy.

\section{Figure 1:}

Distribution of Austrian respondents aged 50 and above by sex and age

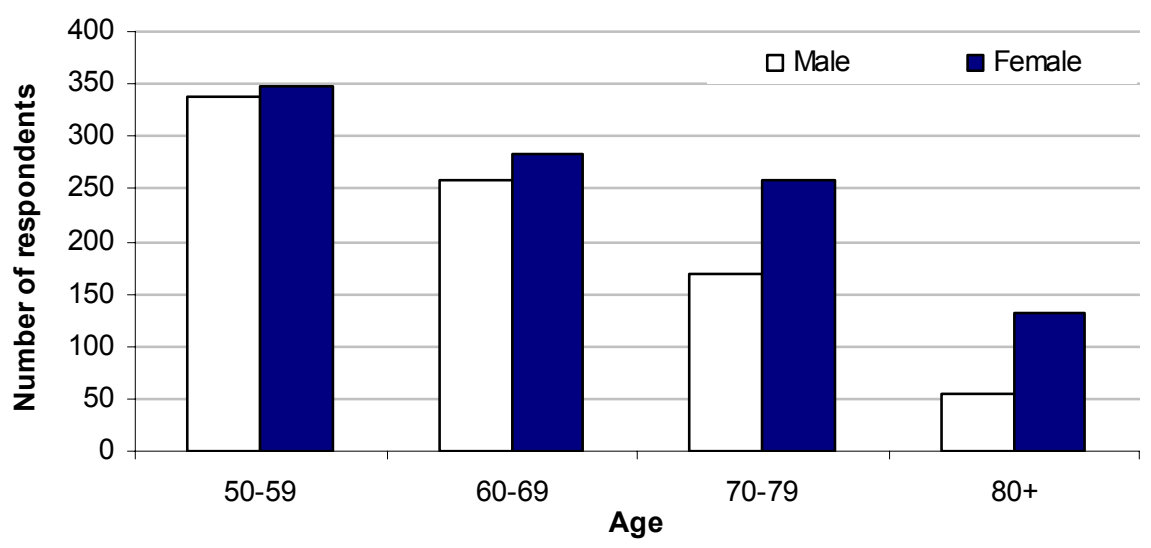

Source: SHARE "Release 2.0.1", weighted data for Austria, own calculations

The economic aspect is not covered here, because it would limit our scope. For more details we refer to Börsch-Supan et al. (2005), for the Austrian data we refer to Buber et al. (2006). Nevertheless, we want to summarise at least the modules that include detailed information on economic variables and indicators: Employment and pensions, financial transfers, household income, consumption and assets. 


\section{Physical health}

Certainly, health is one of the main aspects of ageing and the collected accurate information on physical health, linked with economic and social information provides a perfect basis for multidisciplinary research. SHARE contains a broad range of different health measures, like self-reported general health, self-reported diagnosed chronic conditions or medications, symptoms as well as limitations included in the "Activities of Daily Living" (ADL) and "Instrumental Activities of Daily Living" (IADL). Further aspects of health, such as mental health, physical measurements (hand grip strength and gait speed), body mass index (BMI) and health care are also covered in detail, allowing research on age-related health and morbidity from different angles.

According to their own evaluation, $68 \%$ among men and $74 \%$ of women aged in their fifties perceive their health as "very good" or "good". This proportion decreases with age to $51 \%$ among men and only $26 \%$ among women for respondents aged 80 years and above (Figure 2). Our findings reflect-also for Austria-that men report better health, but have lower life expectancy than women (Case and Paxson 2005). Although self-reported health is an essential indicator, it is a subjective measure and might reflect cultural differences. Jürges (2007) decomposed cross-national differences in self-reported health into parts explained by difference in 'true' health, measured by diagnosed conditions and measurements, and parts explained by cross-cultural differences in response styles and finds that Austrians show no tendency to under- or overestimate their health. Therefore, self-assessed health is a rather objective measure for Austria.

Respondents were also asked whether they had been diagnosed as having had a chronic disease during their lifetime and whether they had ever been bothered by physical symptoms lasting at least six months, choosing from 14 diseases and 11 described symptoms (Mackenbach et al. 2005). Figure 3 shows the prevalence of self-reported chronic diseases for Austria. Among men, the highest rates were found for hypertension, followed by high cholesterol, heart disease and diabetes. Among females, striking numbers suffered from hypertension, followed by high cholesterol, arthritis/rheumatism, and osteoporosis. With regard to cancer, participants were asked in which organ or part of the body they currently had or had had cancer, with 24 possible categories to choose from. Respondents were also asked about medication, namely whether they currently took any medication at least once a week; for answering this question, they could choose from a list of 14 types of drugs. 
Figure 2:

Proportion of respondents with "very good" or "good" self-reported health, Austrians aged 50 and above

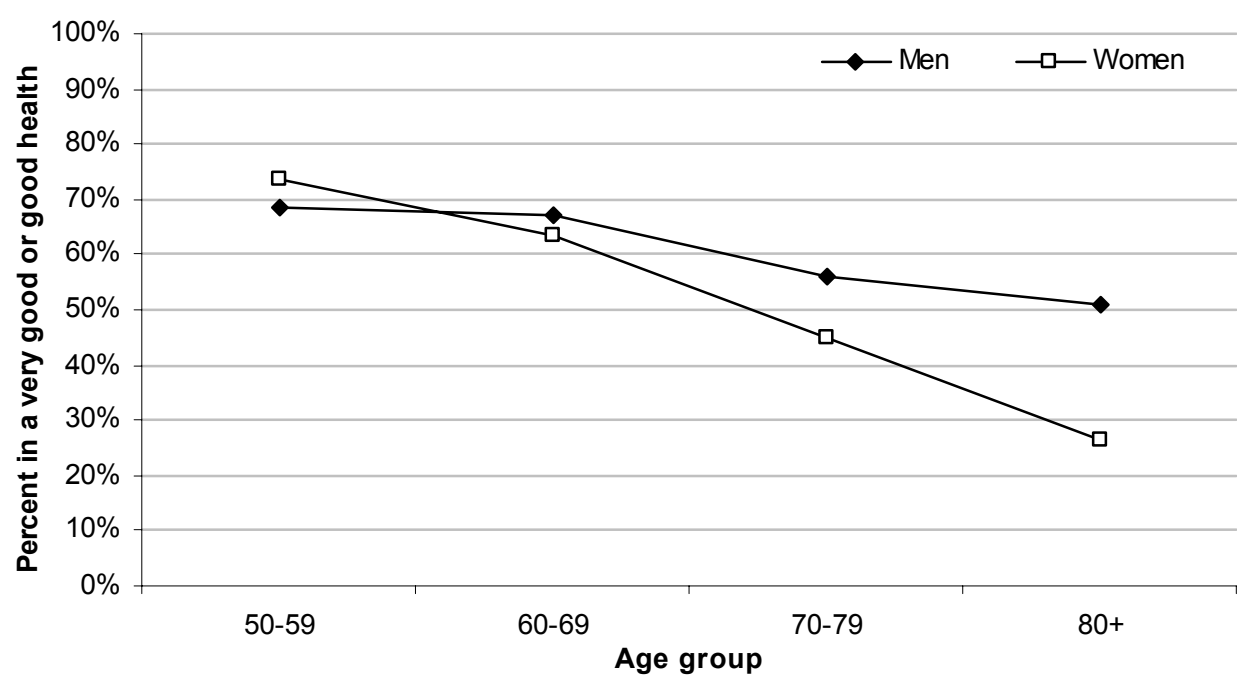

Source: SHARE "Release 2.0.1", weighted data for Austria, own calculations

Figure 3:

Prevalence of self-reported chronic diseases among Austrians aged 50 and above (in per cent)

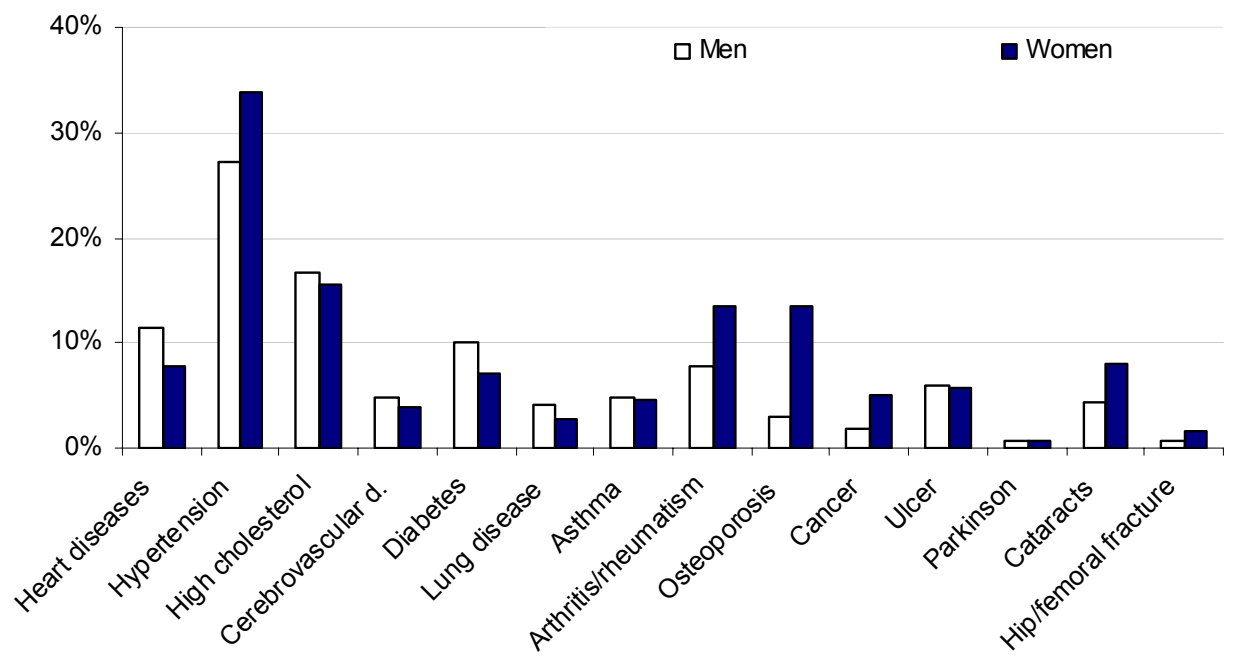

Source: SHARE "Release 2.0.1", weighted data for Austria, own calculations 
Finally, limitations regarding the ability to engage in the typical physical activities of daily life were measured using self-reports. Included were both "Activities of Daily Living" (ADL) - which include dressing, getting in and out of bed, eating, etc. - and "Instrumental Activities of Daily Living" (IADL) such as preparing meals, shopping, making phone calls, etc. According to Lubitz et al. (2003), we created a summary functioning variable incorporating (1) limitations in activities because of health problems and (2) the degree of limitations with mobility, arm functioning and fine motor function. This combination allows to determine the degree of limitations. ${ }^{7}$ The proportion of persons living without limitation decreases with age and is roughly 10 percentage points lower among women than among men (Table 1). Moreover, gender-specific calculations reveal a much higher proportion of women with limitations, especially from the age of 60 onwards: $26 \%$ among men in their sixties but $38 \%$ among female peers reported limitations together with difficulties in mobility and fine motor functions, ADL or IADL or even severe limitations due to health problems (Table 1). The proportion of older persons with (severe) limitations increases to $40 / 52 \%$ for men/women in their seventies and to $46 / 64 \%$ for male/female respondents aged 80 years and above.

Table 1:

Limited activities and degree of limitations among Austrians aged 50 and above

\begin{tabular}{|c|c|c|c|c|c|c|c|}
\hline & Age & Not limited & $\begin{array}{c}\text { Not limited, } \\
\text { difficulties }\end{array}$ & $\begin{array}{l}\text { Limited, no } \\
\text { difficulties }\end{array}$ & Limited & $\begin{array}{c}\text { Severely } \\
\text { limited }\end{array}$ & Total \\
\hline \multirow[t]{5}{*}{ Men } & $50-59$ & $51 \%$ & $10 \%$ & $9 \%$ & $19 \%$ & $11 \%$ & $100 \%$ \\
\hline & $60-69$ & $45 \%$ & $17 \%$ & $13 \%$ & $20 \%$ & $6 \%$ & $100 \%$ \\
\hline & $70-79$ & $32 \%$ & $16 \%$ & $12 \%$ & $26 \%$ & $14 \%$ & $100 \%$ \\
\hline & $80+$ & $22 \%$ & $18 \%$ & $13 \%$ & $24 \%$ & $22 \%$ & $100 \%$ \\
\hline & Total & $43 \%$ & $14 \%$ & $11 \%$ & $21 \%$ & $11 \%$ & $100 \%$ \\
\hline \multirow[t]{5}{*}{ Women } & $50-59$ & $45 \%$ & $17 \%$ & $11 \%$ & $18 \%$ & $9 \%$ & $100 \%$ \\
\hline & $60-69$ & $31 \%$ & $23 \%$ & $9 \%$ & $27 \%$ & $11 \%$ & $100 \%$ \\
\hline & $70-79$ & $21 \%$ & $16 \%$ & $10 \%$ & $35 \%$ & $17 \%$ & $100 \%$ \\
\hline & $80+$ & $9 \%$ & $19 \%$ & $8 \%$ & $31 \%$ & $33 \%$ & $100 \%$ \\
\hline & Total & $30 \%$ & $19 \%$ & $10 \%$ & $26 \%$ & $15 \%$ & $100 \%$ \\
\hline
\end{tabular}

Source: SHARE "Release 2.0.1”, weighted data for Austria, own calculations

Legend: Not limited: Not limited in activities people usually do

Not limited, difficulties: Not limited in activities people usually do, but mobility and fine motor difficulties or ADL or IADL difficulties

Limited, no difficulties: Limited in activities people usually do, but neither mobility nor ADL nor IADL difficulties

Limited: Limited in activities people usually do, and mobility and fine motor difficulties or ADL or IADL difficulties

Severely limited: Severely limited in activities people usually do

7 The summary functioning variable used here was created by Harold Lentzner during his research at the Vienna Institute of Demography in 2007; it is based on Lubitz et al. (2003) but extends the functioning variable used in that publication. 
Older adults who have difficulty with ADLs and IADLs often require personal assistance from relatives, friends, or neighbours to carry out these important tasks. SHARE respondents who reported difficulty with such basic personal tasks as bathing, dressing, and transiting, or household tasks such as preparing a hot meal, shopping, or making telephone calls were asked if they received help with these activities, and if they did, whether it was enough to meet their needs.

Two out of three older Austrians who had problems with one or more ADLs or IADLs said they received personal assistance to do these activities. Among persons with ADL or IADL limitations the proportion who received assistance increased with age, $46 \%$ of those 50-59 said they received help with these activities $^{8}$, but among Austrians age 80 and older, 86\% were aided (Figure 4). There was no difference between older men and women in the proportion receiving assistance. The number and nature of the difficulties was related to the level of assistance. Austrians who had difficulty with three or more ADLs were more likely to say they received aid than those who had fewer ADL difficulties or only had difficulty with IADLs. And as for the nature of the ADL difficulty, persons who had difficulty walking across the room, bathing and eating were more likely to receive assistance than those who did not have these difficulties. Of those who do get help, most said that the assistance they received usually or always met their needs. Only about $10 \%$ of older Austrians who receive assistance said the help was only sometimes or hardly ever sufficient.

\section{Figure 4:}

Proportion of respondents with one or more ADL/IADL difficulties who received help with the activities

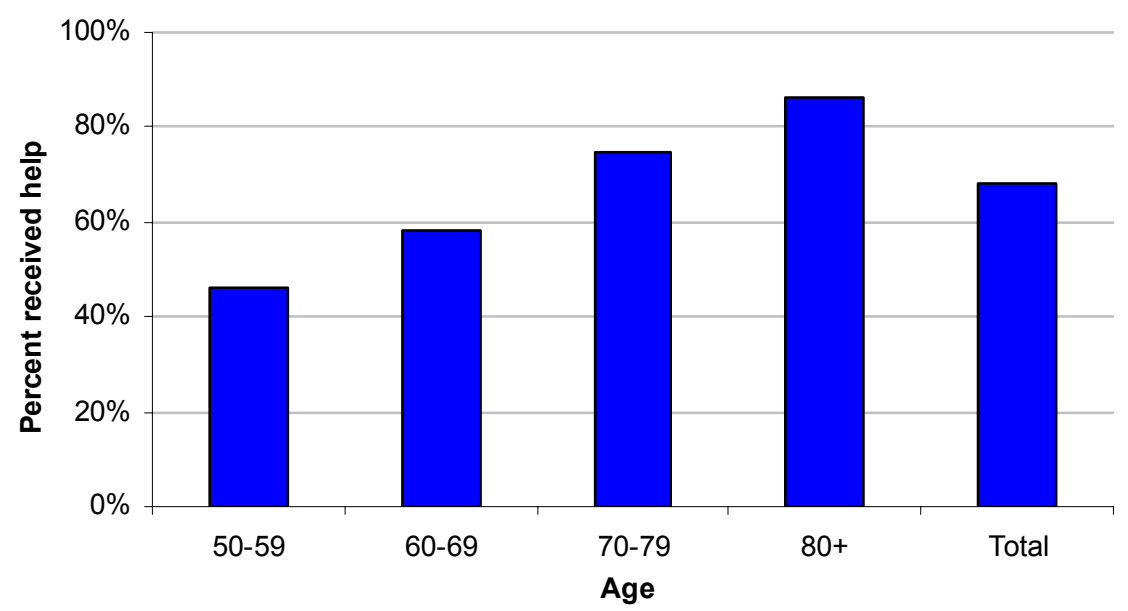

Source: SHARE "Release 2.0.1", weighted data for Austria, own calculations.

8 The low percentage is partly due the fact that $14 \%$ of persons aged in their fifties with limitations gave no answer at all when asked if they received personal assistance. 


\section{Mental health}

A person's mental health is an important aspect of everyday life and the relevance of mental health as an indivisible part of health is widely accepted. Mental illness can drastically reduce the quality of life of those affected and their families. Mental disorders are common; estimates for the adult population in the EU that has suffered from some form of mental ill-health or mental disorder within the past 12 months range from $20 \%$ to 27\% (EC 2004; Wittchen and Jacobi 2005). Late-life depression is a common disorder affecting $10 \%$ to $15 \%$ of the population above age 65 (Beekman et al. 1999).

SHARE devotes one module to mental health and, for the first time, provides comparable data on mental health and depressions for Europe. A first comparative analysis of SHARE is consistent with previous studies and shows that depressions are prevalent among women, older people, those who are not married, and those who live alone (Dewey and Prince 2005). Moreover, Buber and Engelhardt (2006) found a protective function of children: on the one hand, childless persons had higher levels of depression; on the other hand, only few contacts with their children also had a negative effect on mental health of older persons. They also showed that the presence of a spouse or partner had a much stronger protective effect on the mental health of older persons than the presence of or the contact with children.

In the Austrian SHARE data, we also found strong gender differences: $23 \%$ among men and $37 \%$ among women declared to have felt sad or depressed within the past month. Especially women aged 70 years or older admitted to have had such feelings in a much higher percentage than did men (Figure 5).

SHARE contains two alternative depression scales, CES-D and EURO-D and we provide descriptive results with EURO-D. All eligible individuals were asked whether they have felt sad or depressed, whether they have felt guilty, have had problems with sleeping and whether they have kept up their interests. Other questions concerned pessimism, suicidality, irritability, appetite, fatigue, concentration, enjoyment, tearfulness. Based on these 12 items, the EURO-D scale (Prince et al. 1999) can be calculated, with a high score indicating a high level of depression. Dewey and Prince (2005) suggest to set a threshold at score 3 and define clinically significant depression as a EURO-D score greater than 3 . Accordingly, $12 \%$ among men and $26 \%$ among women would be classified as clinically depressed (Table 2). 
Figure 5:

Percentages of Austrians aged 50+ who had felt sad or depressed within the past month

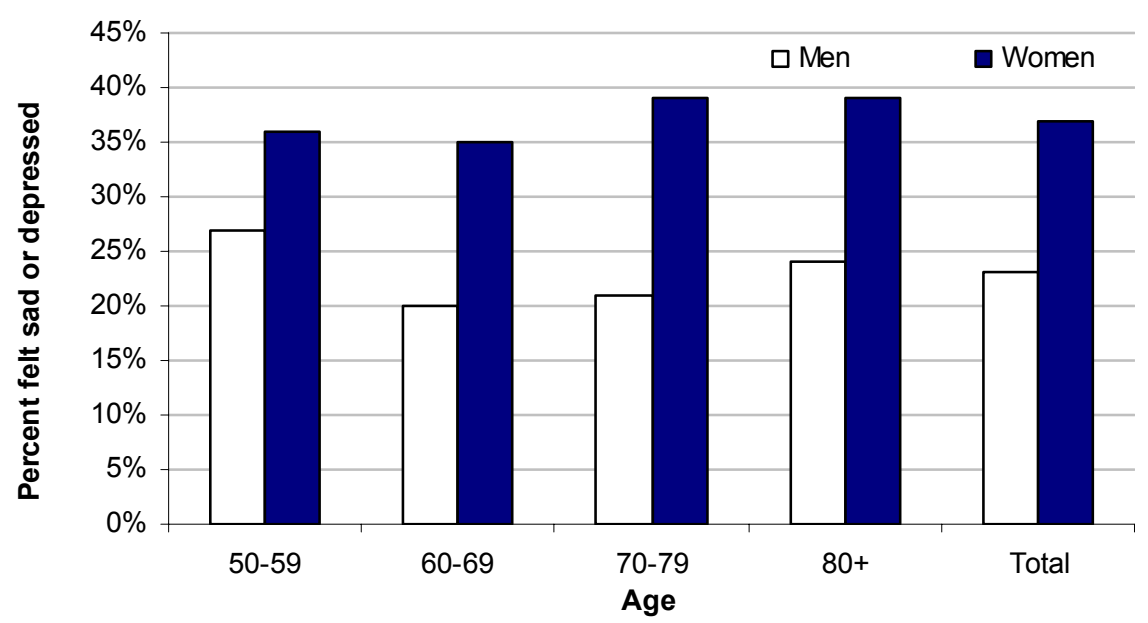

Source: SHARE "Release 2.0.1", weighted data for Austria, own calculations

Table 2:

Distribution of depressive symptoms according to the EURO-D scale among Austrians aged 50 and above

\begin{tabular}{cccccccc}
\hline \multirow{4}{*}{ Men } & & 0 & 1 & 2 & 3 & $4+$ & Total \\
& $50-59$ & $35 \%$ & $26 \%$ & $16 \%$ & $10 \%$ & $14 \%$ & $100 \%$ \\
& $60-69$ & $40 \%$ & $25 \%$ & $20 \%$ & $10 \%$ & $6 \%$ & $100 \%$ \\
& $70-79$ & $35 \%$ & $23 \%$ & $18 \%$ & $7 \%$ & $17 \%$ & $100 \%$ \\
& $80+$ & $25 \%$ & $20 \%$ & $25 \%$ & $7 \%$ & $23 \%$ & $100 \%$ \\
& Total & $36 \%$ & $25 \%$ & $18 \%$ & $9 \%$ & $12 \%$ & $100 \%$ \\
Women & $50-59$ & $28 \%$ & $25 \%$ & $14 \%$ & $11 \%$ & $22 \%$ & $100 \%$ \\
& $60-69$ & $28 \%$ & $22 \%$ & $16 \%$ & $10 \%$ & $25 \%$ & $100 \%$ \\
& $70-79$ & $19 \%$ & $23 \%$ & $20 \%$ & $11 \%$ & $28 \%$ & $100 \%$ \\
& $80+$ & $19 \%$ & $11 \%$ & $18 \%$ & $16 \%$ & $37 \%$ & $100 \%$ \\
& Total & $24 \%$ & $22 \%$ & $17 \%$ & $11 \%$ & $26 \%$ & $100 \%$ \\
\hline
\end{tabular}

Source: SHARE "Release 2.0.1", weighted data for Austria, own calculations Note: EURO-D is a measure of depression based on 12 depressive symptoms.

Whereas the above questions concern mental health during the last month, SHARE includes also information on depression in the past. Respondents were explicitly asked whether they ever suffered from symptoms of depression which lasted at least two weeks and-if so-whether they had had a treatment for depression. In Austria, 12\% among men and 22\% among women reported to have suffered from depression. Interestingly, women were more often treated for their depression which might indicate a higher acceptance of depression among women (Figure 6). 
Figure 6:

Prevalence of depression and depression lasting at least two weeks and treatment for depression by a family doctor or psychiatrist among Austrians aged 50 and above

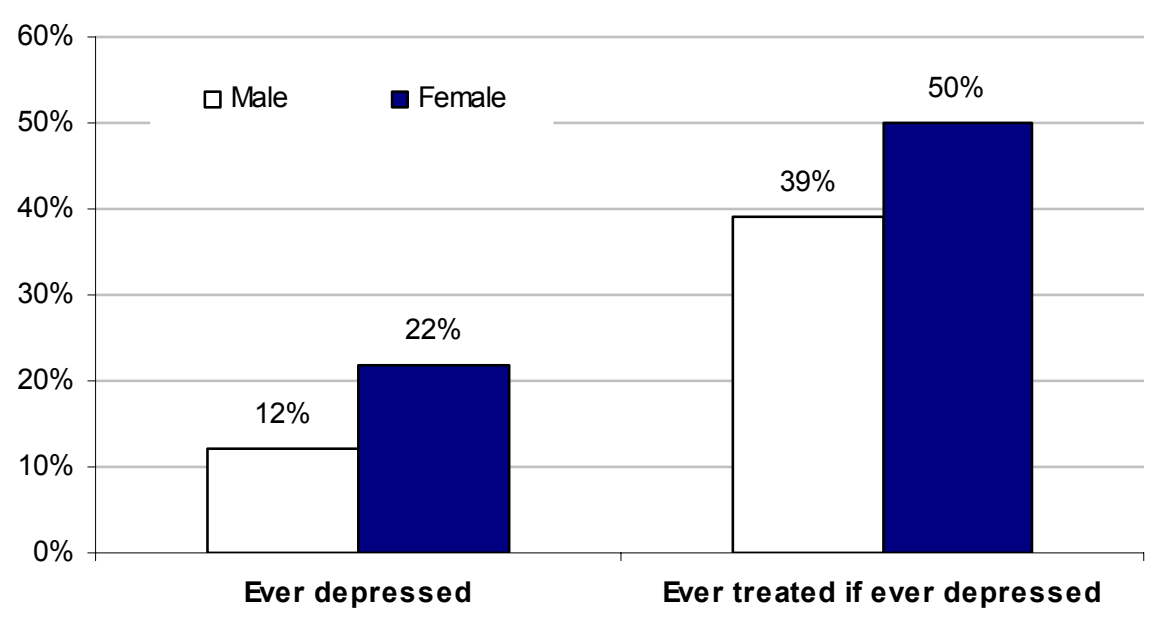

Source: SHARE "Release 2.0.1", weighted data for Austria, own calculations

\section{Cognitive function}

Besides physical and mental health, cognitive ability is an important aspect of daily living. Apart from self-rated reading and writing skills, SHARE includes five more objective measures of cognitive functioning: orientation, memory, verbal fluency, numeracy and recall. ${ }^{9}$ Whereas orientation is a useful instrument for the diagnosis of severe cognitive impairment, memory, verbal fluency, numeracy and recall are more sophisticated instruments for measuring cognitive abilities.

As Figure 7 shows, the average number of words immediately recalled decreases strongly with age from 5.6 to around 3.7, the more distant memory measured with recall decreased from 4.0 to 2.0 words. Further analyses revealed that men have higher scores for numerical knowledge and verbal fluency, whereas men and women do not differ according to memory and recall. The decline with age takes place at the same pace for men and women.

9 "Memory" gives the number of words the interviewee can recall out of a list of the following ten items: Butter, arm, letter, queen, ticket, grass, corner, stone, book, stick.

"Verbal fluency" denotes the number of different animals the interviewee can name within one minute.

"Numeracy" specifies mathematical performance, more exactly knowledge on percentage calculation.

"Recall" states the number of words out of the list of ten words the interviewee can recall after a certain delay of time. 
Figure 7:

Memory and recall among Austrians aged 50 and above

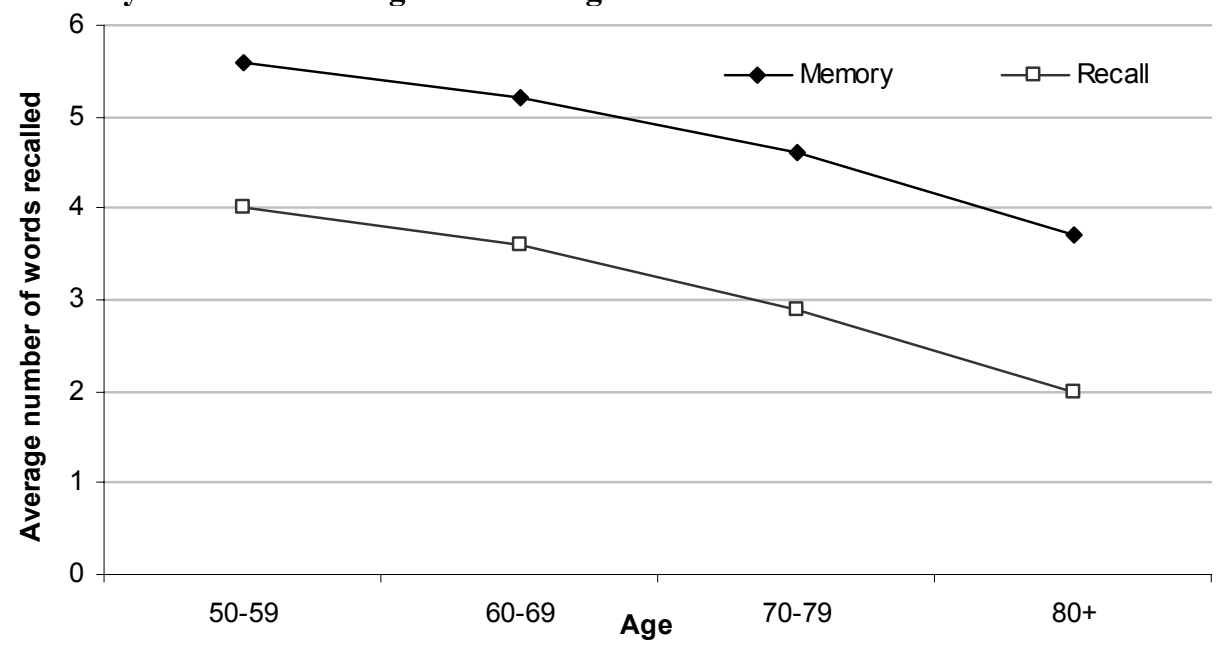

Source: SHARE "Release 2.0.1", weighted data for Austria, own calculations

Note: See the definition of "memory" and "recall" in Footnote 9.

Education is crucial for cognitive functioning. Figure 8 depicts educational differences in numerical knowledge and shows better cognitive functioning for higher educational levels; results for short-term memory, more distant memory and verbal fluency show similar trends.

Figure 8:

Numerical knowledge by educational level among Austrians aged 50 and above

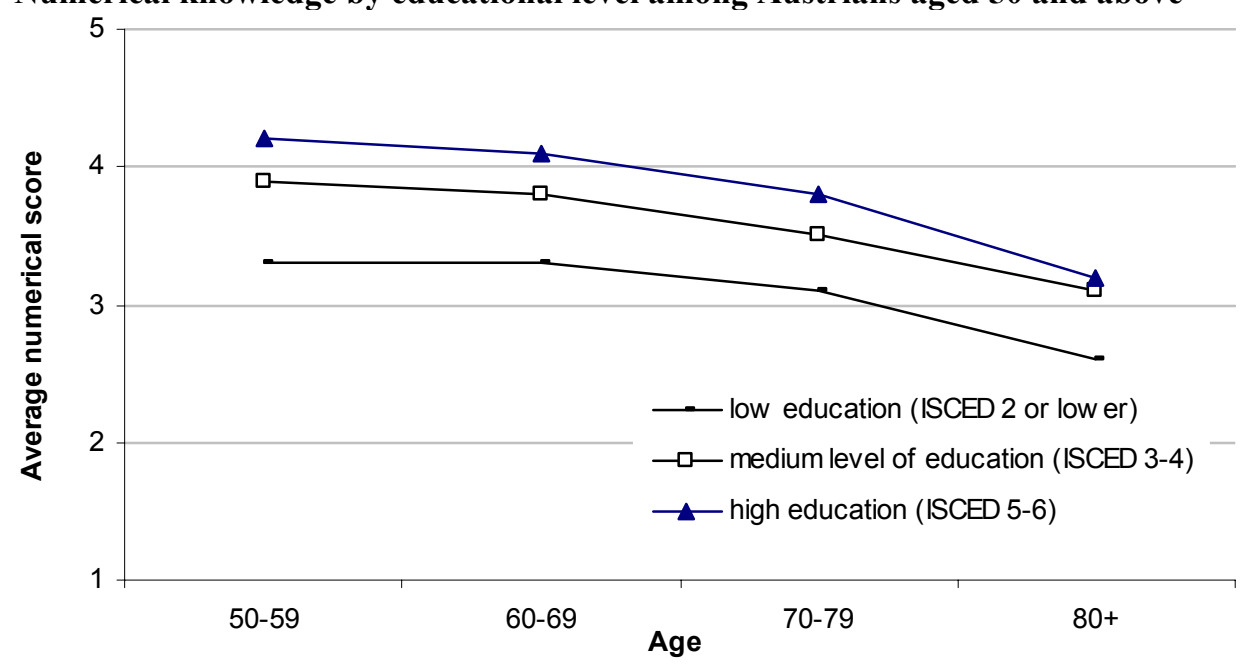

Source: SHARE "Release 2.0.1", weighted data for Austria, own calculations

Note: "Numeracy" indicates mathematical performance based on four questions. The score ranges from 1 to 5 , the higher the score, the better the numerical knowledge. 


\section{Social support}

Older people give to and receive practical help from other family members in many ways. The SHARE questionnaire investigated three crucial areas of family support: personal care received from outside the household, care given to others outside the household, and looking after grandchildren. Moreover, given and received help within the household (asked for persons not living in a single household only) rounds up the various aspects of providing and giving help.

Help from outside the household focused on (1) personal care, e.g., dressing, bathing or showering, eating, getting in or out of bed, using the toilet, (2) practical household help, e.g., home repairs, gardening, transportation, shopping, household chores, and (3) help with paperwork, e.g., filling out forms, settling financial or legal matters. About $29 \%$ of all respondents reported that they personally or their spouses or partners had received help from any family member, friend or neighbour outside the household during the past twelve months. As Figure 9 shows, older persons had received help more often than younger persons (Figure 9).

Older persons not only receive but also provide help and therefore all eligible persons were asked whether and whom they had given help to, as well as the type and frequency of help. These questions were asked for up to three family members outside the household. In Austria, about $24 \%$ of all respondents reported to have given help, whereby older persons gave help less often than younger persons (Figure 9).

\section{Figure 9:}

Proportion of respondents who had received help from outside the household and who had helped others outside the household

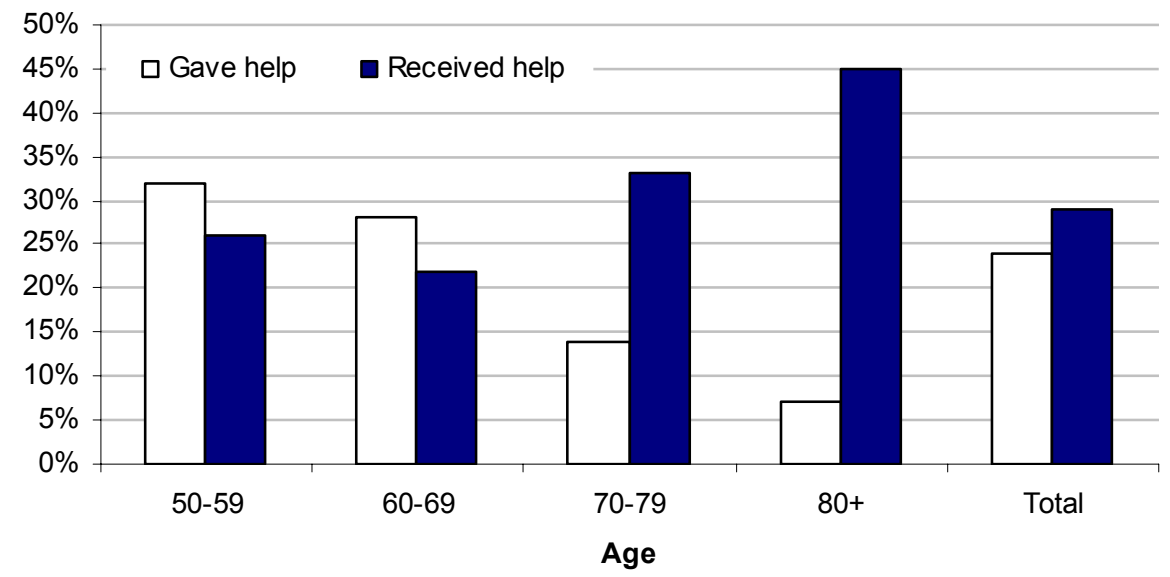

Source: SHARE "Release 2.0.1", weighted data for Austria, own calculations 
It is worthwhile looking at the provision of help by the composition of the household. $36 \%$ of older persons living alone, $21 \%$ of couples and $26 \%$ of those living in family households receive help from outside the household. Children living outside the household provide an essential support for their parents. Interestingly, the network of older persons is rather diverse, especially of those living alone or in a family household: Three out of ten receiving support have more than one helper (Figure 10).

\section{Figure 10:}

Number and identity of the helpers from outside the household by household composition

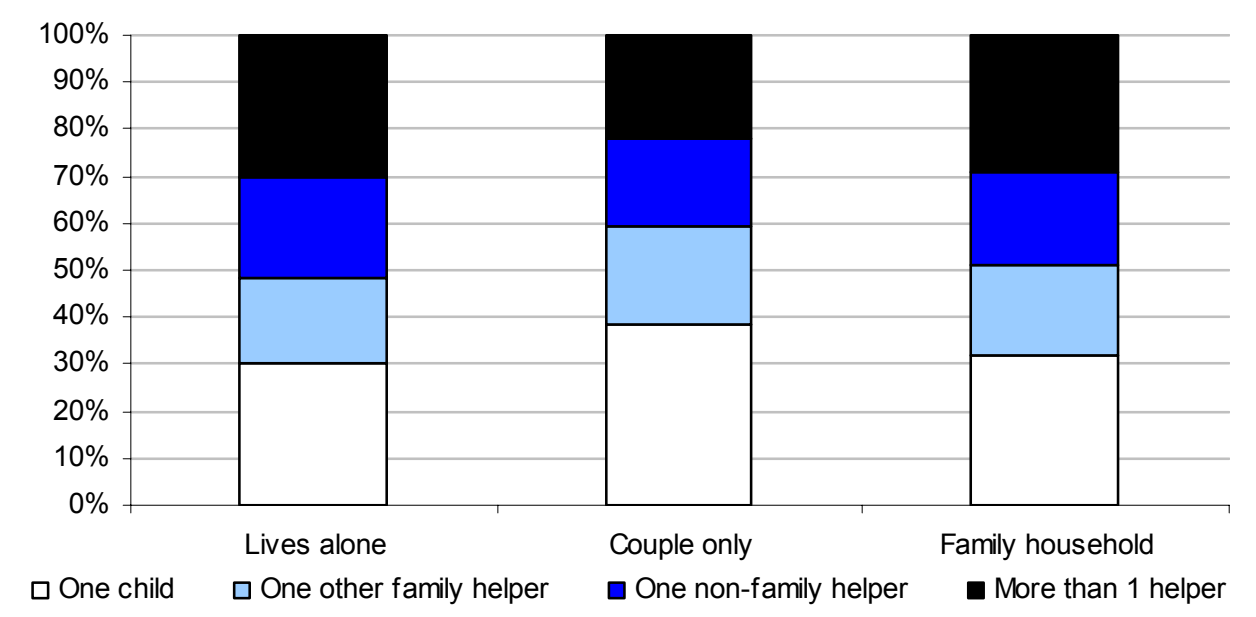

Source: SHARE "Release 2.0.1", weighted data for Austria, own calculations

Remark: Persons receiving help from outside the household; not including the minority (1\%) living in other forms of household

\section{Drop-off questionnaire}

The computer-assisted personal interviewing (CAPI) programme of SHARE was supplemented by a self-completion paper-and-pencil questionnaire, the so-called drop-off questionnaire. It included questions that might be particularly sensitive for the respondent (e.g., on social and psychological well-being, health care, religiosity and political affiliation). The preliminary drop-off response rate for all countries was $81.3 \%$. In Austria, $90.0 \%$ of all individuals who had completed the interview returned the drop-off questionnaire.

One focus in the drop-off questionnaire was on psychological well-being with questions on satisfaction with life and a list of statements that describe life or how a person feels. Individuals had to answer to what extent they agreed with statements such as "My age prevents me from doing the things I would like to do" or "I feel that life is full of opportunities". More general questions on physical 
well-being captured an aspect of health not covered in the physical health module by asking questions on chronic or long-term illness. Individuals had to answer to what extent they agreed to statements such as "My sleep was restless", "I felt that everything I did was an effort" or "I had a lot of energy".

"As populations age, health systems must adapt and develop approaches that meet the needs of frail patients with multiple chronic conditions. Geriatric assessment, prevention, rehabilitation and integrated care are key components of this evolution" (Santos-Eggimann et al. 2005, p. 141). The need for indicators of quality of care delivered to older persons in health care systems is recognised, and SHARE is the first data source that includes such indicators for European comparisons. Three groups of indicators for the quality of care are contained in the drop-off questionnaire: (1) indicators of geriatric assessment in primary care (e.g., information collected by physicians, advice for physical activity, anamnesis of falls, examination of balance, weight control, medical anamnesis of drugs), (2) screening and prevention (e.g., flu vaccination, eye examination, mammograms, endoscopic examinations, tests for occult blood), and (3) quality of care for arthritic pain (Santos-Eggimann et al. 2005).

As an example we show the responses to the statement "My age prevents me from doing the things I would like to do". We found that agreement increases with increasing age. Whereas $30 \%$ of the Austrians in their fifties feel sometimes or often limited by their age, $75 \%$ among those aged 80 years and more perceive it as a burden that prevents them from doing the things they would like to do (Figure 11).

\section{Figure 11:}

"My age prevents me from doing the things I would like to" (responses among Austrians aged 50 and above)

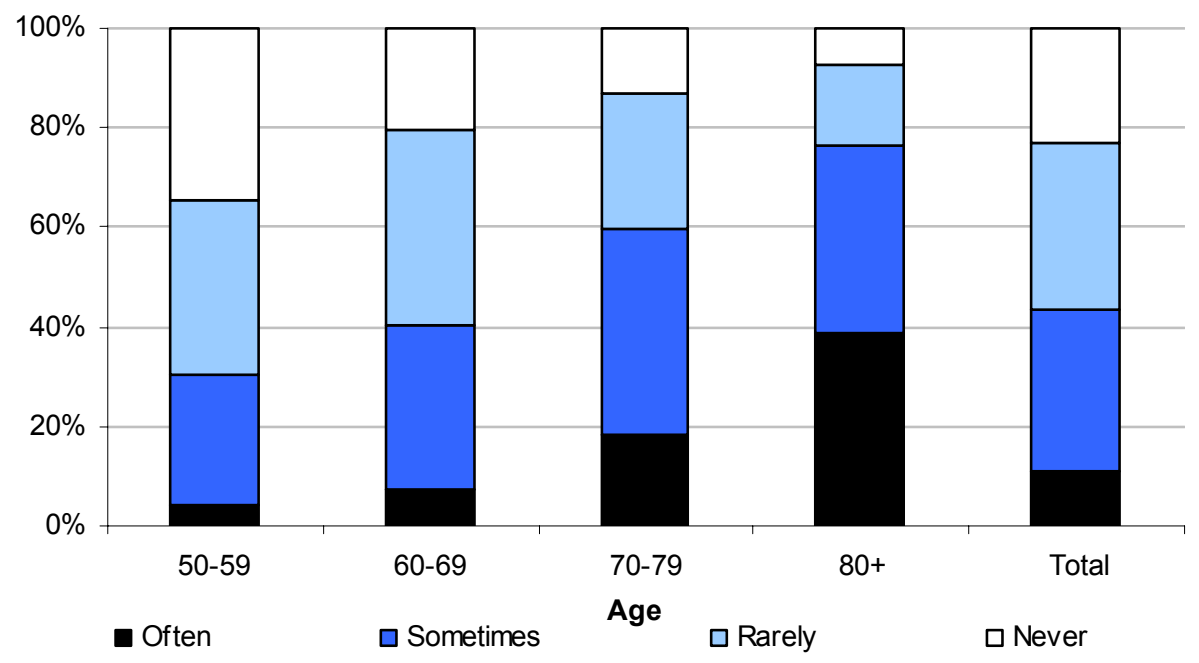

Source: SHARE "Release 2.0.1", weighted data for Austria, own calculations, men and women Note: The graph does not include missing responses. 


\section{Acknowledgements}

I want to thank Alexia Prskawetz and an unknown referee for comments. Special thanks to Harold Lentzner and Elsie Pamuk who also contributed to this paper. Moreover, I am indebted to Werner Richter for editing this article.

\section{References}

Beekman, A. T. F., J. R. M. Copeland, and M.J. Prince. 1999. "Review of Community Prevalence of Depression in Later Life." British Journal of Psychiatry 174: 307-311.

Börsch-Supan, A. 2005 "Introduction to SHARE and its First Results." Slides presented by Axel Börsch-Supan during the SHARE Launch in Brussels, 28th April 2005 (http://www.share-project.org/index.php?page=Launch\&menue=10\&sub=)

Börsch-Supan, A., A. Brugiavini, H. Jürges, J. Mackenbach, J. Siegrist, and G. Weber (eds.) 2005. Health, Ageing and Retirement in Europe - First Results from the Survey of Health, Ageing and Retirement in Europe. Mannheim: MEA Eigenverlag.

Börsch-Supan, A. and H. Jürges (eds.) 2005. The Survey of Health, Ageing and Retirement in Europe - Methodology. Mannheim: MEA Eigenverlag.

Buber, I. 2006. "SHARE Codebook." Research Report 30, Vienna, Vienna Institute of Demography.

Buber, I., A. Prskawetz, H. Engelhardt, F. Schwarz, and R. Winter-Ebmer. 2006. "Survey of Health, Ageing and Retirement in Europe. SHARE. First Results for Austria." Research Report 31. Vienna, Vienna Institute of Demography.

Buber, I. and H. Engelhardt. 2006. "Children and Mental Health of Elderly." European Demographic Research Paper 4. Vienna, Vienna Institute of Demography.

Case, A. and C. Paxson. 2005. "Sex differences in morbidity and mortality." Demography 42: 189-214.

Dewey, M. E. and M. J. Prince. 2005. "Mental Health.” In: A. Börsch-Supan et al. (eds.) Health, Ageing and Retirement in Europe - First Results from the Survey of Health, Ageing and Retirement in Europe. Mannheim: MEA Eigenverlag, pp. 108-117.

EC. 2004. Action for Mental Health. Activities co-funded from the European Community Public Health Programmes 1997-2004. Luxembourg: European Commission, Health and Consumer Protection DG.

Jürges, H. 2007. "True health vs. response styles: Exploring cross-country differences in self-reported health." Health Economics, 16(2): 163-178.

Lubitz, J, L. Cai, E. Kramarow, and H. Lentzner. 2003. "Health, Life Expectancy, and Health Care Spending among the Elderly." New England Journal of Medicine 349: 1048-55.

Mackenbach, J., M. Avendano, K. Andersen-Ramberg, and A. R. Aro. 2005. "Physical Health.” In: A. Börsch-Supan et al. (eds.) Health, Ageing and Retirement in EuropeFirst Results from the Survey of Health, Ageing and Retirement in Europe. Mannheim: MEA Eigenverlag, pp. 82-88.

Prince, M., F. Reischies, A. Beekman, R. Fuhrer, C. Jonker, S.-L. Kivela, B. A. Lawlor, A. Lobo, H. Magnusson, M. Fichter, H. van Oyen, M. Roelands, I. Skoog, C. Turrina, and J. Copeland. 1999. "Development of the EURO-D Scale - a European Union 
Initiative to Compare Symptoms of Depression in 14 European Centres." British Journal of Psychiatry 174: 330-338.

Santos-Eggimann B., J. Junod, and S. Cornaz. 2005. "Health Services Utilisation in Older Europeans." In: A. Börsch-Supan et al. (eds.) Health, Ageing and Retirement in Europe - First Results from the Survey of Health, Ageing and Retirement in Europe. Mannheim: MEA Eigenverlag, pp. 133-140.

Scherbov, S. and M. Mamolo. 2006. "Probabilistic Population Projections for the EU-25." European Demographic Research Papers 1. Vienna, Vienna Institute of Demography.

Wittchen, H.-U. and F. Jacobi. 2005. "Size and Burden of Mental Disorders in Europe - a Critical Review and Appraisal of 27 Studies.” European Neurophsychopharmacology 15(4): 357-37. 